\title{
Working memory performance is related to intrinsic resting state functional connectivity changes in community-dwelling elderly cohort
}

\author{
Céline Charroud ${ }^{\mathrm{a}, \mathrm{c}, \mathrm{d}}$, Emmanuelle Le Bars ${ }^{\mathrm{a}}$, Jérémy Deverdun ${ }^{\mathrm{a}, \mathrm{e}, \mathrm{f}}$, Jason Steffener ${ }^{\mathrm{g}}$, François Molino ${ }^{\mathrm{a}, \mathrm{e}, \mathrm{h}}$, \\ Meriem Abdennour ${ }^{\mathrm{b}}$, Florence Portet ${ }^{\mathrm{b}, \mathrm{i}}$, Alain Bonafe ${ }^{\mathrm{a}}$, Yaakov Stern ${ }^{\mathrm{g}}$, Karen Ritchie ${ }^{\mathrm{b}, \mathrm{i}}$, \\ Tasnime N. Akbaraly ${ }^{\mathrm{c}, \mathrm{d}, \mathrm{j}, 1}$, Nicolas Menjot de Champfleur ${ }^{\mathrm{a}, \mathrm{k}, *, 1}$ \\ a Institut d'Imagerie Fonctionnelle Humaine, Department of Neuroradiology, Montpellier University Hospital Center, Gui de Chauliac Hospital, Montpellier, France \\ ${ }^{\mathrm{b}}$ Inserm, Unit 1061, Neuropsychiatry: Epidemiological and Clinical Research, La Colombière Hospital, University of Montpellier I, France \\ ${ }^{\mathrm{c}}$ Inserm U 1198, University of Montpellier II, France \\ ${ }^{\mathrm{d}}$ EPHE, Paris, France \\ e Laboratoire Charles Coulomb, CNRS UMR 5221 - Université Montpellier II, Montpellier, France \\ ${ }^{\mathrm{f}}$ Intrasense, Montpellier, Hérault, France \\ ${ }^{g}$ Cognitive Neuroscience Division, Department of Neurology, Columbia University, New York, United States \\ ${ }^{\mathrm{h}}$ Institut de Génomique Fonctionnelle, UMR 5203 - INSERM U661 - Université Montpellier II - Université Montpellier I, France \\ ${ }^{\mathrm{i}}$ Faculty of Medicine, Imperial College, London, United Kingdom \\ ${ }^{\mathrm{j}}$ Department of Epidemiology and Public Health, University College London, London, United Kingdom \\ ${ }^{\mathrm{k}}$ Team "Plasticity of Central Nervous System, Stem Cells and Glial Tumors", U1051, Institut of Neurosciences of Montpellier, Saint Eloi Hospital, Montpellier, France
}

\section{A R T I C L E I N F O}

Article history:

Received 9 October 2015

Revised 19 May 2016

Accepted 20 May 2016

Available online 24 May 2016

\section{Keywords:}

Aging

Brain mapping

Functional MRI

Memory: working memory

Neural plasticity

\begin{abstract}
A B S T R A C T
Characterization of normal age-related changes in resting state brain networks associated with working memory performance is a major prerequisite for studying neurodegenerative diseases. The aim of this study was to investigate the relationship between performing a working memory task (under MRI) and resting-state brain networks in a large cohort of healthy elderly subjects $(n=337)$.

Functional connectivity and interactions between networks were assessed within the default mode (DMN), salience (SN), and right and left central executive (CEN) networks in two groups of subjects classed by their performance (low and high).

The low performance group showed lower functional connectivity in both the DMN and SN, and higher functional connectivity in the right and left CEN compared to the high performance group. Overall the functional connectivity within the DMN and the CEN were correlated.

The lower functional connectivity within the DMN and SN in the low performance group is suggestive of altered attentional and memory processes and/or altered motivation. The higher functional connectivity within the CEN could be related to compensatory mechanisms, without which the subjects would have even lower performances. The correlation between the DMN and CEN suggests a modulation between the lower functional connectivity within the DMN and the higher functional connectivity within the CEN when performance is reduced.

Finally, this study suggests that performance modifications in healthy elderly subjects are associated with reorganization of functional connectivity within the DMN, SN, and CEN.
\end{abstract}

(c) 2016 Elsevier Inc. All rights reserved.

\footnotetext{
Abbreviations: CEN, central executive network; DMN, default mode network; DR, degree of representativity; DU, degree of unicity; P, performance between low and high levels of difficulty (one and six letters); $\mathrm{RT}_{\mathrm{L} 1}$, mean correct response time in level 1 (one letter); $\mathrm{RT}_{\mathrm{L} 6}$, mean correct response time in level 6 (six letters); $\mathrm{SN}$, salience network.

* Corresponding author at: Institut d'Imagerie Fonctionnelle Humaine, Hôpital Gui de Chauliac, Service de Neuroradiologie, 80 avenue Augustin Fliche, 34295 Montpellier cedex 5, France.

E-mail address: nicolasdechampfleur@orange.fr (N. Menjot de Champfleur).

1 Nicolas Menjot de Champfleur and Tasnime N. Akbaraly contributed equally to this work.
}

\section{Introduction}

Resting state functional magnetic resonance imaging (fMRI) studies in the field of aging have raised significant interest since the activation of specific networks engaged under resting conditions have been associated with increased rates of mild cognitive impairment (Koch et al., 2010; Rombouts, Barkhof, Goekoop, Stam, \& Scheltens, 2005; Sorg et al., 2007) and Alzheimers (Wang et al., 2006; Wu et al., 2011). Resting-state networks could also 
underlie a broad range of functions (memory, attention, motor, and sensory), involved in working memory (Fox \& Raichle, 2007; Fox et al., 2005; Greicius, Krasnow, Reiss, \& Menon, 2003; SalaLlonch et al., 2012; Uddin \& Menon, 2010). Indeed, short-term memory is impaired in Alzheimer's disease and at the earliest stages of the disease (Baddeley \& Hitch, 1974; Huntley \& Howard, 2010).

Age-related cognitive deficits have been associated with atrophy, amyloid protein deposition, accumulation of white matter hyperintensities, reduced glucose metabolism and modifications of the resting state networks (prefrontal cortex, precuneus, parietal lobule, cingulate cortex) (Benson et al., 1983; Birdsill et al., 2014; Buckner et al., 2005; Hafkemeijer, van der Grond, \& Rombouts, 2012; Minoshima et al., 1997; Serra et al., 2011; Solé-Padullés et al., 2009). In addition to exploring the role of resting-state networks in dementia and cognitive decline, the relationship between resting state fMRI and working memory performances merits further investigation in non-pathological aging to improve our understanding of the neural bases underlying working memory processes.

Three main brain networks involved in resting-state and working memory tasks have been identified in the literature: the central executive network (CEN), the salience network (SN), and the default mode network (DMN) (Chen et al., 2013; Menon \& Uddin, 2010; Smith et al., 2014; Weissman-Fogel, Moayedi, Taylor, Pope, \& Davis, 2010).

The spatial distribution of the CEN is composed of the dorsolateral prefrontal cortices and the posterior parietal cortices (Liao et al., 2010; Menon \& Uddin, 2010; Seeley et al., 2007; Weissman-Fogel et al., 2010). This network could be involved in cognitive processing for working memory, judgment, decisionmaking, and attention (Asplund, Todd, Snyder, \& Marois, 2010; Corbetta \& Shulman, 2002; Curtis \& D'Esposito, 2003; Koechlin \& Summerfield, 2007; Miller \& Cohen, 2001).

The SN includes the limbic and paralimbic structures especially the bilateral insula and anterior cingulate (Cabeza \& Nyberg, 2000; Heine et al., 2012; Rytty et al., 2013). These regions are involved in emotional, sensory, working memory, and attentional processes (Bunge, Ochsner, Desmond, Glover, \& Gabrieli, 2001; Cabeza \& Nyberg, 2000; Critchley, Wiens, Rotshtein, Ohman, \& Dolan, 2004; Crottaz-Herbette \& Menon, 2006; Johnson et al., 2006; Seeley et al., 2007; Taylor, Seminowicz, \& Davis, 2009).

The last network, the DMN, involves the posterior cingulate gyrus, the inferior parietal lobules, and the medial prefrontal cortex (Greicius et al., 2003; Uddin, Clare Kelly, Biswal, Castellanos, \& Milham, 2009; Wu et al., 2011). The specific role of the DMN has yet to be fully elucidated. It seems to be involved in behavioral planning, self-evaluation, and memory encoding (Damoiseaux et al., 2006; Greicius, Srivastava, Reiss, \& Menon, 2004; Koch et al., 2010; Raichle et al., 2001; Sestieri, Corbetta, Romani, \& Shulman, 2011).

These three networks have been shown to work simultaneously, particularly during working memory tasks. Sridharan et al. have shown that the anterior insula induces an increased activation in CEN and decreased activation in DMN during resting-state (Sridharan, Levitin, \& Menon, 2008). Furthermore, a negative correlation has been reported between DMN and CEN activations while a positive correlation has been exhibited between SN and CEN activations during working memory tasks and even at rest (Bressler \& Menon, 2010; Chen et al., 2013; Di \& Biswal, 2013, 2014; Habeck et al., 2005; Menon \& Uddin, 2010; Orliac et al., 2013; Palaniyappan \& Liddle, 2012; Pochon et al., 2002; Seeley et al., 2007). In other words, when the SN and CEN show an increased activation, the DMN typically exhibits a decreased activation. Therefore, the SN could initiate a switch between the CEN and the DMN. These interactions at rest could be essential to promote efficient cognitive processing during cognitive tasks.

Resting state fMRI studies have also reported altered functional connectivity in each of these three networks in cognitively healthy elderly individuals. These studies showed lower functional connectivity within the DMN associated with decreased performance during working memory and executive tasks (Andrews-Hanna et al., 2007; Duchek et al., 2013). A similar lower functional connectivity has been reported in the SN (Duchek et al., 2013; Onoda, Ishihara, \& Yamaguchi, 2012). Another study revealed higher functional connectivity within the right CEN associated with lower working memory performances (Sala-Llonch et al., 2012). The authors suggest that this finding could be ascribed to compensatory processes involved is case of impaired working memory.

However, these studies involved small numbers of subjects $(n<73)$ and did not focus on the interaction between these three networks, which is essential if we are to understand the neural basis of working memory.

We hypothesized that individuals with low working memory performance would exhibit lower functional connectivity within both the DMN and SN and higher functional connectivity within the CEN compared to individuals with higher performance. With this in mind, we aimed to investigate the relationship between working memory task performances and functional connectivity within the CEN, SN, and DMN, and the interaction between these networks during resting-state fMRI in a large cohort of healthy elderly subjects.

\section{Methods}

\subsection{Subjects}

The data was derived from the ongoing prospective Montpellier-Three-City study (The 3C Study Group, 2003) in which 2259 volunteers (recruited from the electoral rolls), aged 65 yearold and over, underwent standardized neurological examinations in a dedicated clinical research facility. The clinical examinations were undertaken at baseline (1999-2001) and 2, 4, 7, 10 and 12 years. At 12-year follow-up, participants who were free of dementia and had a Mini Mental State Examination MMSE (Folstein, Folstein, \& McHugh, 1975) score over 24 were invited to undergo an MRI and complementary clinical examination as part of the CRESCENDO (Cognitive REServe and Clinical ENDOphenotype) study $(n=380)$ (Charroud et al., 2015). The clinical examination was carried out approximately 8 months before the MRI examination. The diagnosis of dementia was based on a 3-step procedure. First, trained psychologists administered a battery of neuropsychological tests detailed elsewhere (Akbaraly et al., 2009). Second, all the participants were examined by a neurologist. Finally, an independent committee of neurologists reviewed all potential cases of dementia to obtain a consensual diagnosis according to the criteria of the Diagnostic and Statistical Manual of Mental Disorders, fourth edition. Similar procedures were performed at each phase over the 12-years of follow-up for incident dementia screening. Cases of AD were classified according to the National Institute of Neurological and Communicative Disorders and Stroke - Alzheimer's Disease and Related Disorders Association (McKhann et al., 1984) and cases of mixed/vascular dementia according to the National Institute of Neurological Disorders and Stroke - Association Internationale pour la Recherche en l'Enseignement en Neurosciences criteria (Román et al., 1993).

The study protocol was approved by the ethics committee of the University-Hospital of Bicêtre, and written informed consent was obtained from each participant. Characteristics of the 380 
CRESCENDO participants have been compared to the characteristics of dementia-free participants of the Montpellier-Three-City study who underwent the $12-y$ follow-up examination but who were not included in the CRESCENDO study. Recorded clinical data were: laterality (Edinburgh handedness inventory), Body Mass Index, educational level, current lifestyle, MMSE and cardiovascular disease. The 380 volunteers were more likely to be women, younger, with higher educational achievement and with higher cognitive performances in the Mini Mental State Examination (results not shown, available on request).

\subsection{MRI data acquisition}

At the 12-year follow-up, whole brain MR images were acquired using a 3-Tesla magnet (Skyra, Siemens, Erlangen, Germany) equipped with a 32-channel receive-only head coil.

Magnitude and phase images of the magnetic field were acquired with a gradient echo-echo planar imaging (GE-EPI) sequence $(\mathrm{TR}=436 \mathrm{~ms}$, TE1 $=4.92 \mathrm{~ms}$, TE2 $=7.38 \mathrm{~ms}$, voxels size: $2.56 \times 2.56 \times 3 \mathrm{~mm}$, flip angle $60^{\circ}$ ).

High-resolution anatomical images were acquired using a 3D magnetization-prepared, rapid acquisition gradient echo (MPRAGE) sequence with the following parameters: TR $=1690 \mathrm{~ms}$; $\mathrm{TE}=2.54 \mathrm{~ms} ; \quad \mathrm{TI}=922 \mathrm{~ms} ; \quad$ Flip angle $9^{\circ} ; \quad$ voxel size: $1 \times 1 \times 1 \mathrm{~mm}$; with 176 slices.

Participants underwent two acquisitions of functional imaging: (1) a fMRI delayed item recognition task and (2) a resting-state gradient echo-echo planar imaging (GE-EPI).

The fMRI delayed item recognition task was exclusively used to assess performance of the subject as described later.

\subsection{1. fMRI delayed item recognition task acquisition}

To ensure that the participants had fully understood the instructions, training sessions were held before the fMRI task.

The fMRI acquisition was done in gradient echo-echo planar imaging (GE-EPI) with the following imaging parameters: $\mathrm{TR}=2000 \mathrm{~ms}, \mathrm{TE}=20 \mathrm{~ms}, 39$ axial slices, slice thickness $3 \mathrm{~mm}$, in plane resolution $2.39 \times 2.39 \mathrm{~mm}$, no interslice gap, interleaved acquisition, flip angle $90^{\circ}$.

The fMRI delayed item recognition task (Charroud et al., 2015; Habeck et al., 2005) consisted of 3 different phases: stimulation, retention, and probe phases. The stimulation phase involved the presentation over $3 \mathrm{~s}$ of an array of one, three, or six capital letters, the participants were instructed to remember these letters. During the retention phase, participants were instructed to focus their gaze on a blank screen during $7 \mathrm{~s}$ and to keep the stimulus items in mind. During the probe phase, a lowercase letter was shown in the center of the screen for three seconds. Participants indicated by pressing a button whether or not the probe matched a letter in the study array (right index finger button press to indicate 'yes' for a positive probe, left index finger button press to indicate 'no' for a negative probe). An inter-trial interval consisting of the presentation of a blank screen for three seconds marked the beginning of each trial. In addition, 70 blank trials (presentation of a blank screen for $2 \mathrm{~s}$ ) were pseudo-randomly interspersed between trials in each run to reduce the likelihood of neurophysiologic responses predictive of the beginning of trials. Ten trials were acquired for each set size $(1,3$, or 6 letters), pseudo-randomly sequenced, leading to 30 trials per run. Participants underwent three successive runs.

The number of letters within each set defined its level of difficulty (i.e. level 1, level 3, and level 6 according to the length of the array), level 1 being the lowest level of difficulty of the task and level 6 being the highest.

\subsubsection{Resting-state acquisition}

During the resting-state acquisition, subjects were instructed to keep their eyes closed and not to think of anything in particular.

Gradient echo-echo planar imaging (GE-EPI) sequence acquisitions were done using the following parameters: TR $=2400 \mathrm{~ms}$, $\mathrm{TE}=30 \mathrm{~ms}$, 39 axial slices, slice thickness $3 \mathrm{~mm}$, in plane resolution $2.39 \times 2.39 \mathrm{~mm}$, no interslice gap, interleaved acquisition, flip angle $90^{\circ}, 200$ volumes, acquisition time $8 \mathrm{~min}$.

\subsection{Statistical analyses}

\subsubsection{Performance assessment using the fMRI delayed item recognition task}

Performances in the fMRI delayed item recognition task (describe in Section 2.3.1) were examined by assessing the variability of the "mean correct response time" (i.e. response time when the answer is correct) between the lowest and highest levels of difficulty (Habeck et al., 2005; Zarahn, Rakitin, Abela, Flynn, \& Stern, 2006, 2007) as following:

$P=\frac{\mathrm{RT}_{\mathrm{L} 6}-\mathrm{RT}_{\mathrm{L} 1}}{\mathrm{RT}_{\mathrm{L} 1}}$

where $P$ is the performance variability between level 6 and level 1 . $\mathrm{RT}_{\mathrm{L} 1}$ and $\mathrm{RT}_{\mathrm{L} 6}$ refer to the mean correct response time in levels 1 and 6 respectively.

Two groups - "high performance" and "low performance" have been defined according to the median value of performance variability between level 6 and level $1(P)$.

\subsubsection{Tests}

To compare characteristics according to the two groups, we performed the $\chi^{2}$ test or Fisher's exact test, when appropriate, for categorical data. Continuous data were analyzed with Wilcoxon's test. All $p$-values were two-sided, and a threshold of 0.05 was considered statistically significant. All analyses were performed using $\mathrm{R}$ software, version 3.0.2.

\subsection{Resting-state data pre-processing}

For each participant, the first five volumes were discarded to allow for equilibration of the magnetic field and the participants' adaptation to the scanning noise (Greicius et al., 2004; Wang et al., 2006; Wu et al., 2011).

We used Statistical Parametric Mapping (SPM8; Wellcome Department of Imaging Neuroscience, London, UK, http:// www.fil.ion.ucl.ac.uk/spm/software/spm8/) (Ashburner, 2012) as implemented in Matlab R2012a (The Mathworks Inc.; MA, USA) for resting-state image preprocessing.

It included corrections of magnetic field distortion, scan acquisition time difference and head motion. Participants with head movements more than $3 \mathrm{~mm}$ in translation mean and/or $3^{\circ}$ in rotation mean were excluded. Co-registration to the individual anatomical image was then performed. The anatomical images were segmented into gray matter, white matter, and cerebrospinal fluid using a unified segmentation algorithm as implemented in the "New segment" function of SPM8. A customized template was created based on the gray matter segmentations using Diffeomorphic Anatomical Registration Through Exponentiated Lie Algebra (DARTEL) (Ashburner, 2007). The anatomical images of each subject were normalized with the template created using DARTEL, and then a mean image of all normalized 3DT1 was performed. Resting-state images were thus spatially normalized to the 3DT1 mean image and spatially smoothed using a Gaussian filter with 
a full width at half maximum of $8 \mathrm{~mm}$ to accommodate interindividual anatomical variability.

Results are all expressed in the Montreal Neurological Institute space.

\subsection{Functional connectivity MRI processing and analysis}

Functional connectivity analysis was then performed in a threestep process including (i) a spatial independent component analysis using the NetBrainWork software (https://sites.google.com/ site/netbrainwork/, Laboratoire d'Imagerie Fonctionnelle, Paris, France) (Perlbarg \& Marrelec, 2009; Perlbarg et al., 2008), (ii) a node selection for each previously mentioned network (salience, central executive, and default mode networks) using the Statistical Parametric Mapping software, and (iii) a correlation analysis using the NetBrainWork software.

\subsubsection{Spatial independent component analysis}

A spatial independent component analysis was performed for each subject independently to extract 40 spatially independent components (Esposito et al., 2005; Perlbarg et al., 2008). Then, a hierarchical clustering algorithm was used to collect independent components of all subjects into cluster or "classes" based on their spatial similarity (i.e. spatial correlation between two independent components). The number of classes was assessed automatically by optimizing the degree of representativity (DR) and degree of unicity (DU) (Coynel et al., 2010; Marrelec et al., 2006, 2008). Considering one patient, the related-dataset should be composed of 40 classes, each class being represented by one component. At the group level, the DR is the number of distinct datasets contributing to a class, divided by the total number of datasets. This score controls the representation of each subject with at least one component in a class. The DU is the number of datasets contributing to the class with only one component, divided by the number of distinct datasets. It controls the contribution of one subject in a class with only one component. An optimal class was characterized by scores equal to 1 for DR and DU. Only classes with DR $>0.5$ and DU $>0.75$ were retained.

Afterward, fixed effect analyses were performed to compute tmaps for each remaining class using a threshold of $p<0.01$ and a minimum cluster size of 5 voxels (uncorrected for multiple comparisons, to keep enough voxels to design the regions of interest) (Louapre et al., 2014; Marcotte, Perlbarg, Marrelec, Benali, \& Ansaldo, 2013; Marsolais, Perlbarg, Benali, \& Joanette, 2014). These $\mathrm{t}$-maps represent functionally coherent brain networks across the entire sample.

Each map was compared visually to descriptions of restingstate networks previously found in healthy subjects in order to identify the functional networks to which they correspond (Menon \& Uddin, 2010; Onoda et al., 2012; Weissman-Fogel et al., 2010; Xue et al., 2012). We selected manually the two maps which best corresponded to the default mode $(D R=0.83$ and $\mathrm{DU}=0.98)$ and salience network ( $\mathrm{DR}=0.69$ and $\mathrm{DU}=0.75)$. The map related to the central executive network (CEN) was not identified but was divided into a right and left lateralized network (right CEN and left CEN) as reported previously (Heine et al., 2012; Sala-Llonch et al., 2012; Xue et al., 2012). Therefore, we selected the right CEN (DR=0.55 and $D U=0.90$ ) and left CEN $(D R=0.55$ and $D U=0.95)$ maps. Finally, these four maps were used for the functional connectivity analyses based on a node (i.e. regions of interest) selection.

\subsubsection{Node selection}

As participants were all healthy individuals and did not significantly differ with respect to age, it seemed more appropriate to select nodes on the map of the entire sample. After the extraction of 40 spatially independent components, the four independent components which represent the SN, right CEN, left CEN, and DMN were identified visually and manually for each subject. The salience network was identified in 326 subjects. The left CEN was identified in 258 subjects. The right CEN was identified in 271 subjects. The default mode network was identified in 332 subjects.

A one-sample t-test was performed on the entire sample using SPM8, to identify the statistically significant nodes of the SN, right CEN, left CEN, and DMN based on the peak voxels (Greicius et al., 2007). A cluster-extent threshold was used for a $p$-value of $<0.0001$ and a minimum cluster size of 50 voxels with a correction for multiple comparisons (family-wise error correction) (Fig. 1).

The right CEN nodes were located in the right dorsolateral prefrontal cortex (MNI coordinates 46, 18, 46) and right inferior parietal cortex $(43,-60,46)$. The left CEN nodes were located in the left dorsolateral prefrontal cortex $(-42,13,45)$ and left inferior parietal cortex $(-42,-64,46)$. The SN nodes were located in the right anterior insula $(44,-8,-1)$ and left anterior insula $(-42,-7,-1)$. The DMN nodes were located in the posterior cingulate/precuneus $(3,-62,25)$, right parietal lobule $(48,-68,29)$, left parietal lobule $(-43,-72,30)$, and medial prefrontal cortex $(-3,55,-5)$.

\subsubsection{Correlation analysis}

In order to assess the functional connectivity within each network, a spatial component analysis was performed using the NetBrainWork software in each group. Nodes of each network were selected manually from MNI coordinates in each group using a sphere of 50 voxels. Then, a CORrection of Structured noise using spatial Independent Component Analysis (CORSICA) was applied to remove components related to cardiorespiratory activity and/or to head movements (Perlbarg et al., 2007; Rosso et al., 2013).

Functional connectivity indices were based on Pearson's correlations between the two time-course of blood oxygen leveldependent signal recorded in the two selected nodes (Biswal, Yetkin, Haughton, \& Hyde, 1995; Coynel et al., 2010; Marrelec et al., 2006). Finally, in the two groups, we reported global correlation within each network, which corresponds to the mean of correlations between all nodes of network of interest. In the same way, global correlation between two networks of interest (i.e. interaction) was reported in the entire cohort.

Statistically significant differences between the two groups were revealed by calculating the evidence $e=10 \log _{10}(p /$ $(1-p))$, where $p$ is the posterior probability of an assertion tested (Coynel et al., 2010; Jaynes, 2003). For example, we can test whether global correlation in the first group is lower than that of the second group. Finally, the evidence, assessed in decibels $(\mathrm{dB})$, represents the ratio of the probability that the assertion is true to the probability that the assertion is false, in a base 10 logarithmic. Consequently, two values of global correlation are deemed to be significantly different when $|e|>10 \mathrm{~dB}$ (i.e. ratio of $10 / 1)$, which corresponds to a probability of $p_{e}>0.909$ that an assertion is true.

\section{Results}

\subsection{Cohort characteristics}

Of the 380 participants who underwent the MRI exam after 12 years of follow-up, 345 subjects performed a resting-state acquisition (23 subjects were excluded due to incomplete acquisition and 12 due to head movements) and 337 subjects performed a fMRI delayed item recognition task ( 35 subjects were excluded due to incomplete acquisition and 8 due to head movements). The 


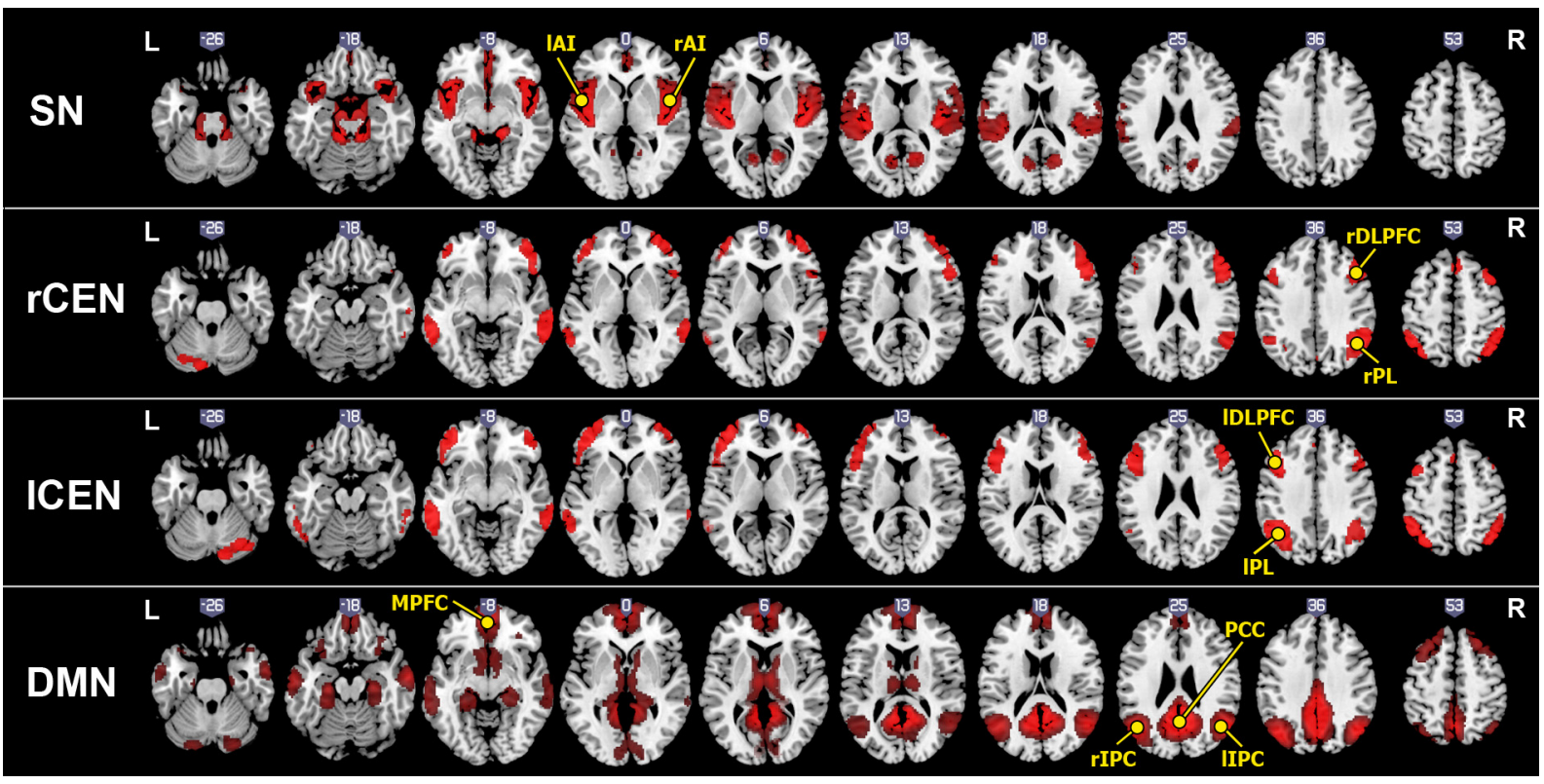

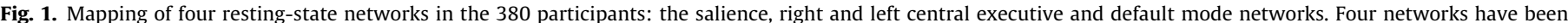

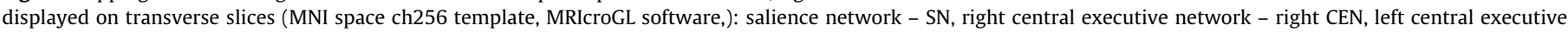

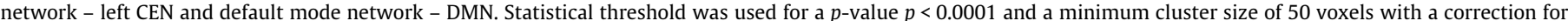

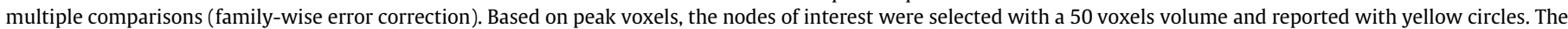

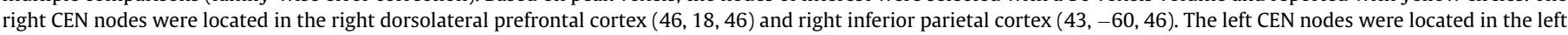

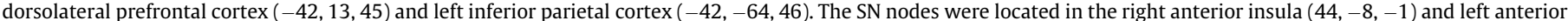

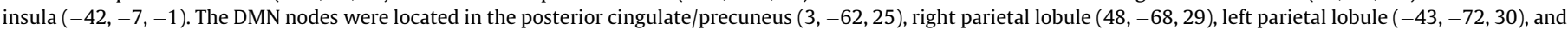

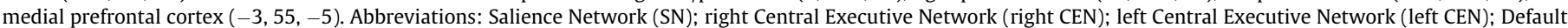

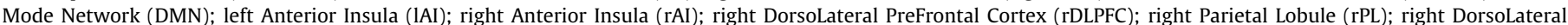

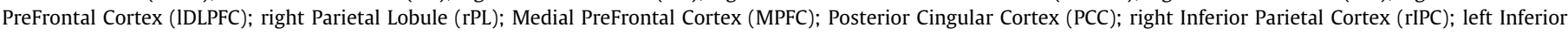
Parietal Cortex (IIPC); Left (L); Right (R).

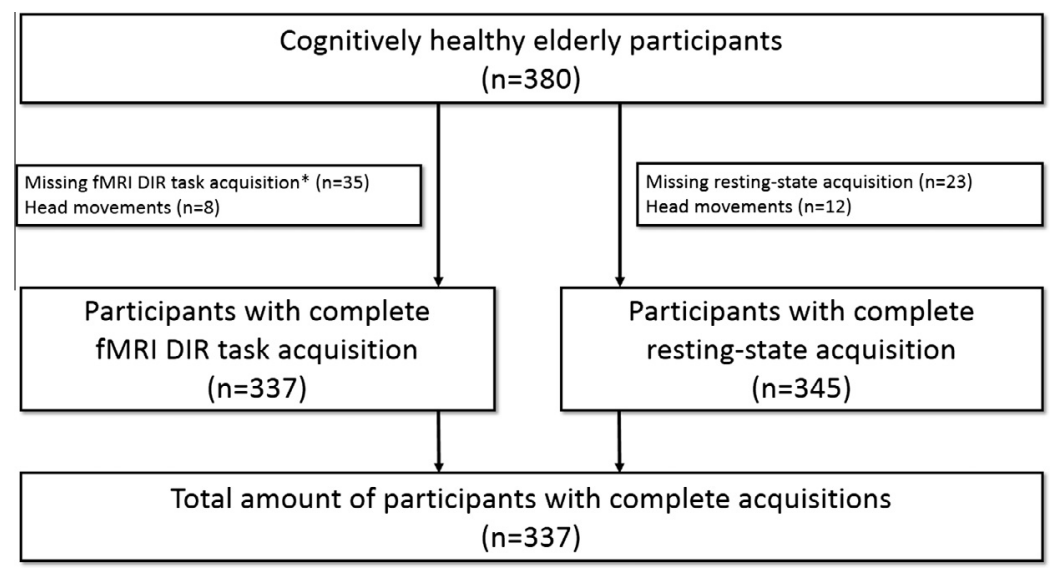

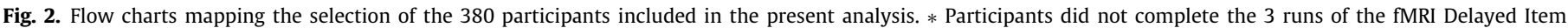
Recognition (DIR) task.

selection of participants included in the present analyses is detailed in the flow-chart diagram (Fig. 2).

Two groups based on fMRI DIR task performances were considered according to the performance variability between two levels of difficulty of the fMRI DIR task.

The high performance group $(n=167)$ was composed of 93 women and 74 men with a mean age of $82.1 \pm 3.8$ years and a mean performance variability of $27.2 \pm 13.3$.

The low performance group $(n=170)$ included 98 women and 72 men, with a mean age of $81.6 \pm 3.6$ years and a mean performance variability of $66.4 \pm 17.5$.

Characteristics of participants according to fMRI DIR task performances are displayed in Table 1 . There was no statistically significant difference between the two groups of performance according to sex $(p=0.07)$, age $(p=0.2)$, laterality $(p=0.7)$, level of education ( $p=0.8)$, current lifestyle $(p=0.1)$, and cognitive performances assessed by the MMSE $(p=0.5)$ and by the National Adult Reading Test (NART), $(p=0.6)$.

\subsection{Functional connectivity analysis}

\subsubsection{Functional connectivity within networks}

For each of the two groups of performance, the global correlation coefficients within the different networks are illustrated in Fig. 3.

Compared to the high performance group, the low performance group showed a significantly lower correlation coefficient within 
Table 1

Characteristics of the two groups according to the fMRI DIR task performances.

\begin{tabular}{|c|c|c|c|}
\hline Variables & $\begin{array}{l}{ }^{*} \text { Low } \\
\text { performance } \\
\text { roup } \\
N=170\end{array}$ & $\begin{array}{l}{ }^{*} \text { High } \\
\text { performance } \\
\text { group } \\
N=167\end{array}$ & $\begin{array}{l}\text { Global } \\
p \text {-value }\end{array}$ \\
\hline Sex, women, $n(\%)$ & $98(58)$ & $93(56)$ & 0.72 \\
\hline Age, mean (SD), years & $81.62(3.56)$ & $82.13(3.80)$ & 0.22 \\
\hline $\begin{array}{l}\text { Laterality, } n(\%) \\
\text { Ambidextrous } \\
\text { Right-handed } \\
\text { Left-handed }\end{array}$ & $\begin{array}{l}5(3) \\
158(93) \\
7(4)\end{array}$ & $\begin{array}{l}7(4) \\
151(90) \\
9(6)\end{array}$ & 0.70 \\
\hline $\begin{array}{l}\text { Education level, } n(\%) \\
\text { Low } \\
\text { Medium low } \\
\text { Medium high } \\
\text { High }\end{array}$ & $\begin{array}{l}32(19) \\
46(27) \\
32(19) \\
60(35)\end{array}$ & $\begin{array}{l}31(19) \\
44(26) \\
38(23) \\
54(32)\end{array}$ & 0.83 \\
\hline $\begin{array}{l}\text { Current lifestyle, } n(\%) \\
\text { Alone }\end{array}$ & $27(16)$ & $38(23)$ & 0.11 \\
\hline $\begin{array}{l}\text { Couple or living with } \\
\text { family members }\end{array}$ & $143(84)$ & $129(77)$ & \\
\hline MMSE, mean (SD) & $27.8(1.6)$ & $27.6(1.7)$ & 0.56 \\
\hline NART, mean (SD) & $22.7(5.4)$ & $22.2(6.2)$ & 0.69 \\
\hline \multicolumn{4}{|c|}{ Percentage of good response, mean (SD) } \\
\hline Letter 1 & $0.97(0.04)$ & $0.97(0.06)$ & 0.53 \\
\hline Letters 3 & $0.97(0.05)$ & $0.95(0.09)$ & 0.15 \\
\hline Letters 6 & $0.86(00.11)$ & $0.86(0.11)$ & 0.61 \\
\hline $\begin{array}{l}\text { Performance variability, } \\
\text { mean (SD) }\end{array}$ & $66.4(17.5)$ & $27.3(13.3)$ & $<0.0001$ \\
\hline
\end{tabular}

The low and high groups were defined according to the median value of the fMRI DIR task performances (median value: 45.89). This performance (i.e. performance variability) was assessed as $P=\left(\mathrm{RT}_{\mathrm{L} 6}-\mathrm{RT}_{\mathrm{L} 1}\right) / \mathrm{RT}_{\mathrm{L} 1}$ where $\mathrm{RT}_{\mathrm{L} 1}$ and $\mathrm{RT}_{\mathrm{L} 6}$ refer to mean correct response time in levels 1 and 6 respectively.

Laterality was assessed by the Edinburgh handedness inventory questionnaire. Education level was classified as low (5 years of schooling or less), medium low (69 years), medium high (10-12 years), and high (more than 12 years). Cognitive deficit was assessed with the use of a Mini Mental State Examination (MMSE). The National Adult Reading Test (NART) was used as a marker of intelligence. Accuracy (Percentage of good response) is reported for each level of difficulty of the fMRI DIR task.

Data are mean (SD) or number of subjects (\%). To compare characteristics between the two groups, we performed the $\chi^{2}$ test or Fisher's exact test, as appropriate, for categorical data. Continuous data were analyzed with Wilcoxon's test. Significance levels are given in $p$-values and considered significant when $p<0.05$.

the DMN (low performance group $r=0.45$, [SD $=0.01$ ], high performance group $\left.r=0.48,[\mathrm{SD}=0.01], p_{\mathrm{e}}=0.96\right)$. Concerning the $\mathrm{SN}$, the low performance group showed a significantly lower correlation coefficient compared to the high performance group (low performance group $r=0.15$, [SD $=0.01$ ], high performance group $r=0.21$, $[\mathrm{SD}=0.01], p_{\mathrm{e}}=0.99$ ).

Contrariwise, within the right-CEN, the low performance group showed a significantly stronger correlation coefficient compared to the high performance group (low performance group $r=0.06$, [SD $=0.02]$, high performance group $r=0.02, \quad[S D=0.01]$, $\left.p_{\mathrm{e}}=0.95\right)$. Regarding the left CEN, the low performance group showed significantly stronger correlation coefficients compared to the high performance group (low performance group $r=0.22$, [SD $=0.02]$, high performance group $r=0.17,[S D=0.02], p_{\mathrm{e}}=0.97$ ).

\subsubsection{Functional connectivity between networks}

Interaction between networks was expressed by the correlation coefficients computed between the four fMRI networks - DMN, SN, right- and left-CEN for the whole cohort (combining the two working memory performance groups). Results are reported in Table 2.

The DMN showed an interaction with left $(r=0.17 ; \mathrm{SD}=0.006)$ and right CENs $(r=0.14$; $\mathrm{SD}=0.006)$. No significant interaction was found between the SN and the other networks (DMN/SN: $r=-0.03$ [SD $=0.006$ ], $r$ CEN/SN: $r=-0.02$ [SD $=0.006$ ], ICEN/SN: $r=-0.014$, $[S D=0.006])$. The left CEN showed no correlation with the right CEN $(r=0.0003 ; \mathrm{SD}=0.006)$.

The interaction between all networks was similar between high and low performance groups (data not shown).

\section{Discussion}

The aim of this study was to explore the relationship between working memory task fMRI performances and functional connectivity within the CEN, SN, and DMN, and the interaction between these networks during resting-state in a large cohort of healthy elderly subjects.

We found that both the DMN and SN have lower functional connectivity in the low performance group compared to the high performance group. Regarding the CEN, we recorded higher functional connectivity in the low performance group compared to the high performance group.

\subsection{Default mode network}

Previous works have highlighted DMN participation in selfevaluation, episodic, and working memory (Gusnard \& Raichle,

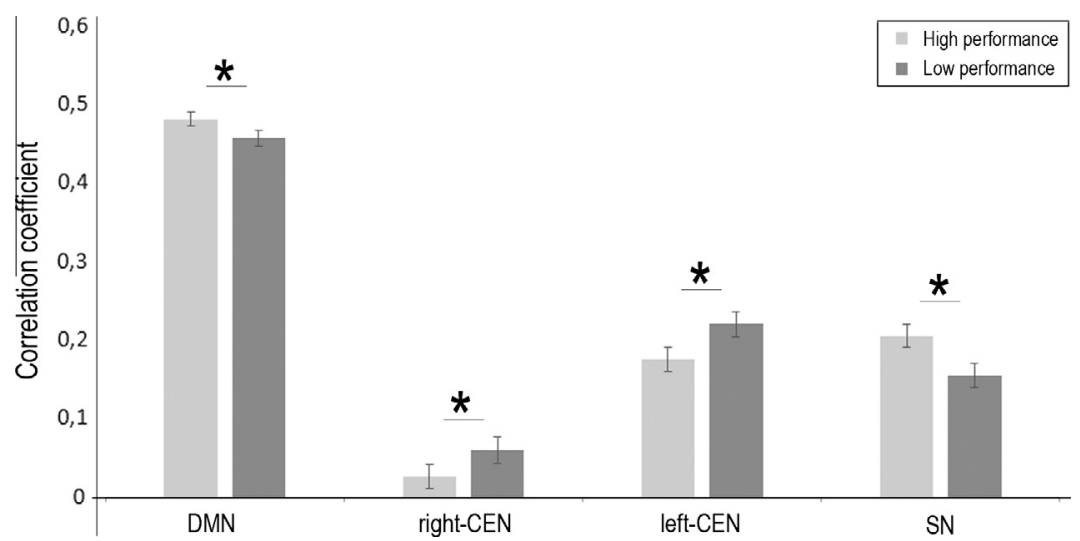

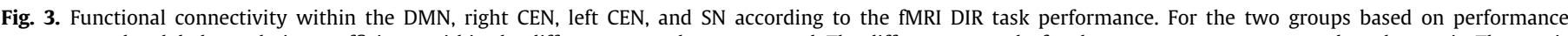

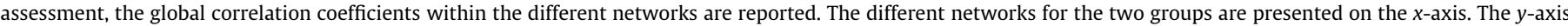

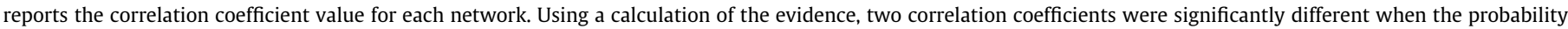

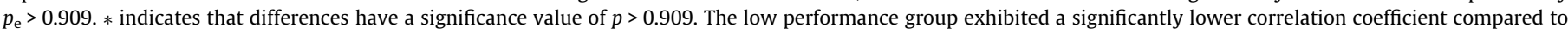

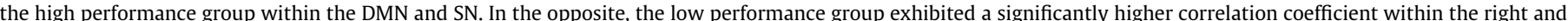

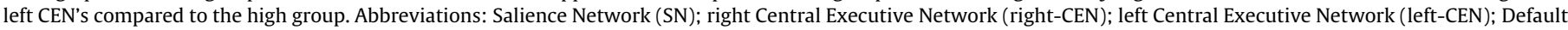
Mode Network (DMN). 
Table 2

Interactions between networks in the entire cohort.

\begin{tabular}{lll}
\hline & Correlation coefficients & SD \\
\hline DMN vs rCEN & 0.14 & 0.006 \\
DMN vs ICEN & 0.17 & 0.006 \\
DMN vs SN & -0.03 & 0.007 \\
rCEN vs ICEN & -0.0003 & 0.006 \\
rCEN vs SN & -0.02 & 0.006 \\
ICEN vs SN & -0.014 & 0.007 \\
\hline
\end{tabular}

Interaction between two networks was expressed with the use of correlation coefficients (SD) between the four networks. The DMN showed a correlation with the right and left CENs. The SN showed no correlation with the other networks especially with the right and left CENs. No correlation was found between the right and left CENs.

Abbreviations: Salience Network (SN); right Central Executive Network (right CEN); left Central Executive Network (left CEN); Default Mode Network (DMN).

2001; Raichle et al., 2001; Rombouts et al., 2005; Sestieri et al., 2011; Shulman et al., 1997). Furthermore, decreased performance has been associated with reduced functional connectivity in the DMN during $n$-back working memory fMRI tasks (Lin, De Pisapia, \& Jovicich, 2011), Stroop task (Duchek et al., 2013), and attentional fMRI tasks (Sala-Llonch et al., 2012).

Our findings concur with these results and suggest that lower functional connectivity in the DMN is related to decreased performances, compatible with a possible alteration in attentional and memory processes in the low performance group.

Furthermore, numerous studies have identified an age-related decreased functional connectivity within DMN areas as frontal gyrus, cingulate gyrus, precuneus and parietal regions (Bergfield, 2013; Damoiseaux et al., 2006, 2008; Greicius et al., 2003; Hafkemeijer et al., 2012). These alterations were more severely decreased in individuals with mild cognitive impairment and Alzheimer's disease (Broyd et al., 2009; Hafkemeijer et al., 2012 Rombouts et al., 2005; Wu et al., 2011). In our study, compared to high performance group, the low performance group seems present the same decreased functional connectivity within DMN. This enhances the hypothesis that an association between resting state DMN connectivity and disease severity.

\subsection{Salience network}

Studies have suggested that the salience network could be involved in working memory processes (monitoring, decisionmaking, cognitive control) and emotional processes (pain, empathy, social rejection) (Bunge et al., 2001; Cabeza \& Nyberg, 2000; Critchley et al., 2004; Crottaz-Herbette \& Menon, 2006; Johnson et al., 2006; Seeley et al., 2007; Taylor et al., 2009). Two studies have shown that functional connectivity within the SN was significantly decreased when performance - not assessed under fMRI was lower in intelligence test (Kohs' block design test scores) (Onoda et al., 2012) and Stroop task (Duchek et al., 2013). By showing that functional connectivity in the SN was lower in the low performance group compared to the high performance group during a fMRI DIR task, our findings could support the involvement of the SN in working memory processes. Other studies have reported that insular and cingulate cortices are involved in emotional and motivational functions (Gu et al., 2012; Jones, Ward, \& Critchley, 2010). Therefore, given that the SN has been located in these brain areas, it might be possible that the lower functional connectivity within the $\mathrm{SN}$ in the low performance group might reflect a decrease in motivation to perform the task (Onoda et al., 2012). This reduced motivation could be due to sleepiness and tiredness. Since the resting-state acquisition was performed after the fMRI DIR task, participants could modify rest activity as a function of their achievement in the task. Compared to the high performance group, the low performance group might exert more effort to perform the task leading to increased sleepiness and fatigue.

\subsection{Central executive network}

Previous studies have suggested that the CEN plays a critical role in working memory, judgment, and decision making (Asplund et al., 2010; Corbetta \& Shulman, 2002; Koechlin \& Summerfield, 2007). It has also been reported that an increase in functional connectivity within the CEN leads to poorer performance in elderly (Sala-Llonch et al., 2012) and middle-aged subjects (Goveas et al., 2013). This concurs with the higher functional connectivity observed in the low performance group for the fMRI DIR task.

Furthermore, several studies have hypothesized that the brain might recruit alternative networks or sets of brain areas to compensate for the loss of cognitive efficiency associated with agerelated decline (Ansado et al., 2013; Habeck et al., 2005; Park \& Reuter-Lorenz, 2009; Reuter-Lorenz \& Cappell, 2008; Stern, 2009). Two forms of compensation have been reported (Stern, 2009): (i) "compensation to improve performance" in which elderly subjects use greater recruitment of the alternate network to improve performance and (ii) "compensation to maintain performance" in which elderly people recruit alternative networks to perform less well.

Therefore, one possible explanation of the higher functional connectivity within the right and left CEN in the low performance group might be that these low performance group participants used a compensatory mechanism to maintain their performances even if they performed the task less well than participants in the high performance group. However, at this stage more investigations are needed to confirm or refute the involvement of compensatory mechanism.

\subsection{Interaction}

There is mounting evidence to suggest that interactions between networks are a key element in elucidating fundamental aspects of human brain function. Although several studies have examined brain networks, including CEN, SN, and DMN, there has been very little work into the simultaneous involvement of these three networks, particularly in the context of working memory tasks (Bressler \& Menon, 2010; Chen et al., 2013; Di \& Biswal, 2013, 2014; Menon \& Uddin, 2010; Palaniyappan \& Liddle, 2012; Sridharan et al., 2008).

Studies into the interactions between the SN and CEN have given controversial results. Two recent studies using resting-state fMRI reported an interaction between the SN and CEN (Goveas et al., 2013; Sridharan et al., 2008), while another study failed to find any such interaction (Onoda et al., 2012). The lack of statistical power due to small cohorts might partly explain the inconsistencies between studies. In the present study, carried out in a larger study population, we did not find any interaction between the $\mathrm{SN}$ and either the right or left CEN. Another explanation for these discordant findings might lie in the different methodologies used to assess connectivity. Indeed, the definition of nodes (i.e. seed) is different between studies: we have used an independent component analysis, whereas other studies used a seed-based voxel wise connectivity analysis (Goveas et al., 2013; Onoda et al., 2012) or a granger causality analysis (Sridharan et al., 2008).

We found an interaction between the DMN and both the left and right CEN. These findings concur with previous studies that reported similar interactions (Liang et al., 2014; Onoda et al., 2012). Furthermore, some studies have shown that activation was typically higher within the SN and CEN and lower within the DMN during fMRI tasks (Bressler \& Menon, 2010; Menon \& 
Uddin, 2010; Palaniyappan \& Liddle, 2012; Sridharan et al., 2008). These authors consequently suggested that the SN could initiate switching between the CEN and DMN. This modulation between the DMN and CEN is compatible with the trend in functional connectivity reported in our results (higher functional connectivity in the CEN and lower functional connectivity in the DMN when performance decreased). However, further analysis is needed to assess whether the lower functional connectivity within the DMN could be associated to the higher functional connectivity within the CEN.

However, we observed no significant interaction between networks in high versus low performance groups. Several hypothesis could be raised to explain this observation. First, the homogeneous sample of healthy elderly participants included in our study whom all had a high level of education and a good cognitive status, could result in similar performances between groups. Second, changes in functional connectivity could first appear within the network, in relation to modification in performances, and at a later stage between networks. Therefore, dealing with healthy elderly subjects, the present study might not be able to point out modifications between networks.

Finally, we focused on participants with normal aging, which could be an indicator of the need to explore with MCI or Alzheimer disease. Indeed, differences in functional connectivity observed in the low performance group compared to the high performance group have the same trends as those observed between mild cognitive impairment and Alzheimer's subjects compared to normal subjects. Studies have reported lower functional connectivity in both the DMN (Greicius et al., 2004; Rombouts et al., 2005; Sorg et al., 2007; Wu et al., 2011) and the SN (Liu et al., 2012), and higher in functional connectivity within the CEN (Goveas et al., 2013; Liu et al., 2012) in patients with mild cognitive impairment or Alzheimers compared with normal subjects. These studies were based on a case-control design and included restricted numbers of subjects. Furthermore, in these studies, performance was not taken into account due to the incapacity of patients with Alzheimer disease to undergo the assessment of task performance under fMRI conditions. Further studies with a longitudinal design are definitely needed to assess whether this specific functional connectivity "pattern" might be a good candidate for discriminating elderly individuals who will maintain their working memory performances throughout aging from those who will suffer from pathological cognitive decline.

While the major strength of our study was to report the functional connectivity and interaction of several networks engaged in resting state and fMRI working memory tasks, in a large group of elderly community-dwellers, we encountered some limitations. First, our study population was composed of volunteers from the Three-City study. They constitute a homogenous white, highlyeducated, healthy elderly population with a high average level of cognitive and physical functioning, thus limiting the generalization of our findings. The assessment of functional connectivity of networks according to working memory task needs to be reproduced in other elderly cohorts, notably with different intellectual levels. Due to a limited acquisition field, a second drawback concerns our inability to explore the involvement of the cerebellum area that has been reported to be linked to performance (Onoda et al., 2012).

\subsection{Limitations}

Some methodological issues may be raised. First, using NEDICA method, we were unable to obtain subject-level connectivity or to consider all voxels within a network individually, rather than as large nodes. This is one inherent limit of the method and consequently, it is not possible to perform a regression analysis on the individual behavioral scores using this algorithm. However, we explored effect of the linearity on the data using other classification algorithms, leading to several groups of performance (i.e. 35 groups). The same analysis performed on those groups suggested a nonlinear effect of performance on connectivity (quadratic trend) and further work on this model may be needed.

Second, considering performance variability in the working memory task as the primary dependent variable, we analyzed this variable in the light of the "cognitive reserve" concept. Stern (2009) suggests that a subject with higher cognitive reserve will show more efficient patterns of task-related activations. For example, the DIR task being effortless for younger subjects, they may be expected to succeed with weaker activations than older subjects. This difference in activation could be related to the concept of neural efficiency, a more efficient network will then show less activation in order to produce the same (or better) level of performance. Therefore, we estimated performance variability between two levels of difficulty of the task to address efficiency. Zarahn et al. (2007) showed that accuracy was not detectably affected by set size in young subjects, unlike old subjects. However, they observed that response time could be a relevant estimation for efficiency. Therefore, as response time seemed more valuable than accuracy, we used this variable in these analyses.

\section{Conclusion}

Our data suggest that, in healthy elderly subjects, functional connectivity assessed by resting-state and performance in a DIR task are linked: (i) in a lower way within the DMN and SN due to alterations in emotional, attentional, and memory processes, and (ii) in an higher way within the right and left CENs that may reflect a compensatory mechanism to maintain performance. An interaction has been identified between the CEN and DMN suggesting a modulation between these two networks.

\section{Acknowledgements}

We thank all participants of the CRESCENDO Study and the CRESCENDO research team comprising research scientists, statisticians, study coordinators, neuropsychologists, general practitioners, data managers, administrative assistants and data entry staff, whom together made the study possible.

This CRESCENDO study was carried out with the financial support of the "ANR - Agence Nationale de la Recherche (MALZ-00701) - The French National Research Agency - and the grants "Chercheur d'Avenir" (R12028FF) and ARPE (Aide à la Recherche en Partenariat avec les Entreprises) (RPH12007F) allocated by the Languedoc Roussillon administrative regional district (France).

\section{References}

Akbaraly, T. N., Portet, F., Fustinoni, S., Dartigues, J.-F., Artero, S., Rouaud, O., ... Berr C. (2009). Leisure activities and the risk of dementia in the elderly: Results from the Three-City study. Neurology, 73(11), 854-861. http://dx.doi.org/10.1212/ WNL.0b013e3181b7849b.

Andrews-Hanna, J. R., Snyder, A. Z., Vincent, J. L., Lustig, C., Head, D., Raichle, M. E., \& Buckner, R. L. (2007). Disruption of large-scale brain systems in advanced aging. Neuron, 56(5), 924-935. http://dx.doi.org/10.1016/j.neuron.2007.10.038.

Ansado, J., Monchi, O., Ennabil, N., Deslauriers, J., Jubault, T., Faure, S., \& Joanette, Y. (2013). Coping with task demand in aging using neural compensation and neural reserve triggers primarily intra-hemispheric-based neurofunctional reorganization. Neuroscience Research (février). http://dx.doi.org/10.1016/j. neures.2013.01.012.

Ashburner, J. (2007). A fast diffeomorphic image registration algorithm NeuroImage, 38(1), 95-113. http://dx.doi.org/10.1016/j. neuroimage.2007.07.007.

Ashburner, J. (2012). SPM: A history. Neurolmage, 62(2), 791-800. http://dx.doi.org/ 10.1016/j.neuroimage.2011.10.025.

Asplund, C. L., Todd, J. J., Snyder, A. P., \& Marois, R. (2010). A central role for the lateral prefrontal cortex in goal-directed and stimulus-driven attention. Nature Neuroscience, 13(4), 507-512. http://dx.doi.org/10.1038/nn.2509. 
Baddeley, A. D., \& Hitch, G. (1974). Working memory. Psychology of Learning and Motivation. G. A. Bower édition.

Benson, D. F., Kuhl, D. E., Hawkins, R. A., Phelps, M. E., Cummings, J. L., \& Tsai, S. Y. (1983). The fluorodeoxyglucose $18 \mathrm{~F}$ scan in Alzheimer's disease and multiinfarct dementia. Archives of Neurology, 40(12), 711-714.

Bergfield, K. L. (2013). Age-related changes in brain connectivity: Alterations of the default mode network<http://arizona.openrepository.com/arizona/handle $10150 / 297022>$.

Birdsill, A. C., Koscik, R. L., Jonaitis, E. M., Johnson, S. C., Okonkwo, O. C., Hermann, B. P., ... Bendlin, B. B. (2014). Regional white matter hyperintensities: Aging, Alzheimer's disease risk, and cognitive function. Neurobiology of Aging, 35(4), 769-776. http://dx.doi.org/10.1016/j.neurobiolaging.2013.10.072.

Biswal, B., Yetkin, F. Z., Haughton, V. M., \& Hyde, J. S. (1995). Functional connectivity in the motor cortex of resting human brain using echo-planar MRI. Magnetic Resonance in Medicine: Official Journal of the Society of Magnetic Resonance in Medicine / Society of Magnetic Resonance in Medicine, 34(4), 537-541.

Bressler, S. L., \& Menon, V. (2010). Large-scale brain networks in cognition: Emerging methods and principles. Trends in Cognitive Sciences, 14(6), 277-290. http://dx.doi.org/10.1016/j.tics.2010.04.004.

Broyd, S. J., Demanuele, C., Debener, S., Helps, S. K., James, C. J., \& Sonuga-Barke, E. J. (2009). Default-mode brain dysfunction in mental disorders: A systematic review. Neuroscience and Biobehavioral Reviews, 33(3), 279-296. http://dx.doi. org/10.1016/j.neubiorev.2008.09.002.

Buckner, R. L., Snyder, A. Z., Shannon, B. J., LaRossa, G., Sachs, R., Fotenos, A. F., ... Mintun, M. A. (2005). Molecular, structural, and functional characterization of Alzheimer's disease: Evidence for a relationship between default activity, amyloid, and memory. The Journal of Neuroscience: The Official Journal of the Society for Neuroscience, 25(34), 7709-7717. http://dx.doi.org/10.1523/ JNEUROSCI.2177-05.2005.

Bunge, S. A., Ochsner, K. N., Desmond, J. E., Glover, G. H., \& Gabrieli, J. (2001) Prefrontal regions involved in keeping information in and out of mind. Brain, 124(10), 2074-2086. http://dx.doi.org/10.1093/brain/124.10.2074.

Cabeza, R., \& Nyberg, L. (2000). Imaging cognition II: An empirical review of 275 PET and fMRI Studies. Journal of Cognitive Neuroscience, 12(1), 1-47.

Charroud, C., Steffener, J., Le Bars, E., Deverdun, J., Bonafe, A., Abdennour, M., .. Akbaraly, T. N. (2015). Working memory activation of neural networks in the elderly as a function of information processing phase and task complexity. Neurobiology of Learning and Memory, 125, 211-223. http://dx.doi.org/10.1016/j. nlm.2015.10.002.

Chen, A. C., Desmond, J., Oathes, J., Chang, C., Bradley, T., Zhou, Z., ... Etkin, A. (2013) Causal interactions between fronto-parietal central executive and default-mode networks in humans. Proceedings of the National Academy of Sciences (novembre). http://dx.doi.org/10.1073/pnas.1311772110. 201311772.

Corbetta, M., \& Shulman, G. L. (2002). Control of goal-directed and stimulus-driven attention in the brain. Nature Reviews Neuroscience, 3(3), 201-215. http://dx.doi. org/10.1038/nrn755.

Coynel, D., Marrelec, G., Perlbarg, V., Pélégrini-Issac, M., Van de Moortele, P. Ugurbil, K., ... Lehéricy, S. (2010). Dynamics of motor-related functiona integration during motor sequence learning. Neurolmage, 49(1), 759-766. http://dx.doi.org/10.1016/j.neuroimage.2009.08.048.

Critchley, H., Wiens, S., Rotshtein, P., Ohman, A., \& Dolan, R. J. (2004). Neural systems supporting interoceptive awareness. Nature Neuroscience, 7(2), 189-195. http://dx.doi.org/10.1038/nn1176.

Crottaz-Herbette, S., \& Menon, V. (2006). Where and when the anterior cingulate cortex modulates attentional response: Combined fMRI and ERP evidence. Journal of Cognitive Neuroscience, 18(5), 766-780. http://dx.doi.org/10.1162 jocn.2006.18.5.766.

Curtis, C. E., \& D'Esposito, M. (2003). Persistent activity in the prefrontal cortex during working memory. Trends in Cognitive Sciences, 7(9), 415-423.

Damoiseaux, J. S., Beckmann, C. F., Sanz Arigita, E. J., Barkhof, F., Scheltens, Ph., Stam, C. J., ... Rombouts, S. A. R. B. (2008). Reduced resting-state brain activity in the "Default Network" in normal aging. Cerebral Cortex (New York, N.Y.: 1991), 18(8), 1856-1864. http://dx.doi.org/10.1093/cercor/bhm207.

Damoiseaux, J. S., Rombouts, S. A. R. B., Barkhof, F., Scheltens, P., Stam, C. J., Smith, S. M., \& Beckmann, C. F. (2006). Consistent resting-state networks across healthy subjects. Proceedings of the National Academy of Sciences of the United States of America, 103(37), 13848-13853. http://dx.doi.org/10.1073/ pnas.0601417103.

Di, X., \& Biswal, B. (2013). Modulatory interactions of resting-state brain functional connectivity. PLoS One, 8(8), e71163. http://dx.doi.org/10.1371/journal. pone.0071163.

Di, X., \& Biswal, B. B. (2014). Modulatory interactions between the default mode network and task positive networks in resting-state. PeerJ, 2, e367. http://dx.doi. org/10.7717/peerj.367.

Duchek, J. M., Balota, D., Thomas, J. B., Snyder, A. Z., Rich, P., Benzinger, T. L.,... Ances, B. M. (2013). Relationship between Stroop performance and resting state functional connectivity in cognitively normal older adults. Neuropsychology, 27 (5), 516-528. http://dx.doi.org/10.1037/a0033402.

Esposito, F., Scarabino, T., Hyvarinen, A., Himberg, J., Formisano, E., Comani, S., ... D Salle, F. (2005). Independent Component Analysis of fMRI Group Studies by SelfOrganizing Clustering. NeuroImage, 25(1), 193-205. http://dx.doi.org/10.1016/j. neuroimage.2004.10.042.

Folstein, M. F., Folstein, S. E., \& McHugh, P. R. (1975). "Mini-mental state". A practical method for grading the cognitive state of patients for the clinician. Journal of Psychiatric Research, 12(3), 189-198.
Fox, M. D., \& Raichle, M. E. (2007). Spontaneous fluctuations in brain activity observed with functional magnetic resonance imaging. Nature Reviews Neuroscience, 8(9), 700-711. http://dx.doi.org/10.1038/nrn2201.

Fox, M. D., Snyder, A. Z., Vincent, J. L., Corbetta, M., Van Essen, D. C., \& Raichle, M. E. (2005). The human brain is intrinsically organized into dynamic, anticorrelated functional networks. Proceedings of the National Academy of Sciences of the United States of America, 102(27), 9673-9678. http://dx.doi.org/10.1073/ pnas.0504136102.

Goveas, J. S., Xie, C., Chen, G., Li, W., Ward, B. D., Franczak, M. B., ... Li, S. (2013) Functional network endophenotypes unravel the effects of apolipoprotein $\mathrm{E}$ epsilon 4 in middle-aged adults. PLoS One, 8(2), e55902. http://dx.doi.org/ 10.1371/journal.pone.0055902.

Greicius, M. D., Flores, B. H., Menon, V., Glover, G. H., Solvason, H. B., Kenna, H., ... Schatzberg, A. F. (2007). Resting-state functional connectivity in major depression: Abnormally increased contributions from subgenual cingulate cortex and thalamus. Biological Psychiatry, 62(5), 429-437. http://dx.doi.org/ 10.1016/j.biopsych.2006.09.020

Greicius, M. D., Krasnow, B., Reiss, A. L., \& Menon, V. (2003). Functional connectivity in the resting brain: A network analysis of the default mode hypothesis. Proceedings of the National Academy of Sciences of the United States of America, 100(1), 253-258. http://dx.doi.org/10.1073/pnas.0135058100.

Greicius, M. D., Srivastava, G., Reiss, A. L., \& Menon, V. (2004). Default-mode network activity distinguishes Alzheimer's disease from healthy aging: Evidence from functional MRI. Proceedings of the National Academy of Sciences of the United States of America, 101(13), 4637-4642. http://dx.doi.org/10.1073/ pnas.0308627101.

Gu, X., Gao, Z., Wang, X., Liu, X., Knight, R. T., Hof, P. R., \& Fan, J. (2012). Anterior insular cortex is necessary for empathetic pain perception. Brain: A Journal of Neurology, 135(Pt 9), 2726-2735. http://dx.doi.org/10.1093/brain/aws199.

Gusnard, D. A., \& Raichle, M. E. (2001). Searching for a baseline: Functional imaging and the resting human brain. Nature Reviews Neuroscience, 2(10), 685-694. http://dx.doi.org/10.1038/35094500.

Habeck, C., Rakitin, B. C., Moeller, J., Scarmeas, N., Zarahn, E., Brown, T., \& Stern, Y. (2005). An event-related fMRI study of the neural networks underlying the encoding, maintenance, and retrieval phase in a delayed-match-to-sample task. Cognitive Brain Research, 23(2-3), 207-220. http://dx.doi.org/10.1016/j. cogbrainres.2004.10.010.

Hafkemeijer, A., van der Grond, J., \& Rombouts, S. A. R. B. (2012). Imaging the default mode network in aging and dementia. Biochimica et Biophysica Acta (BBA) Molecular Basis of Disease, 1822(3), 431-441. http://dx.doi.org/10.1016/j. bbadis.2011.07.008.

Heine, L., Soddu, A., Gomez, F., Vanhaudenhuyse, A., Tshibanda, L., Thonnard, M., ... Demertzi, A. (2012). Resting state networks and consciousness. Frontiers in Psychology, 3(août). http://dx.doi.org/10.3389/fpsyg.2012.00295.

Huntley, J. D., \& Howard, R. J. (2010). Working memory in early Alzheimer's disease: A neuropsychological review. International Journal of Geriatric Psychiatry, 25(2), 121-132. http://dx.doi.org/10.1002/gps.2314.

Jaynes, E. T. (2003). Probability theory: The logic of science.Cambridge, UK; New York, NY: Cambridge University Press.

Johnson, M. K., Raye, C. L., Mitchell, K. L., Touryan, S. R., Greene, E. J., \& NolenHoeksema, S. (2006). Dissociating medial frontal and posterior cingulate activity during self-reflection. Social Cognitive and Affective Neuroscience, 1(1), 56-64. http://dx.doi.org/10.1093/scan/nsl004.

Jones, C. L., Ward, J., \& Critchley, H. D. (2010). The neuropsychological impact of insular cortex lesions. Journal of Neurology, Neurosurgery \& Psychiatry, 81(6), 611-618. http://dx.doi.org/10.1136/jnnp.2009.193672.

Koch, W., Teipel, S., Mueller, S., Buerger, K., Bokde, A. L. W., Hampel, H., ... Meindl, T. (2010). Effects of aging on default mode network activity in resting state fMRI: Does the method of analysis matter? NeuroImage, 51(1), 280-287. http://dx.doi. org/10.1016/j.neuroimage.2009.12.008.

Koechlin, E., \& Summerfield, C. (2007). An information theoretical approach to prefrontal executive function. Trends in Cognitive Sciences, 11(6), 229-235. http://dx.doi.org/10.1016/j.tics.2007.04.005.

Liang, P., Li, Z., Deshpande, G., Wang, Z., Hu, X., \& Li, K. (2014). Altered causal connectivity of resting state brain networks in amnesic MCI. PLoS One, 9(3), e88476. http://dx.doi.org/10.1371/journal.pone.0088476.

Liao, W., Chen, H., Feng, Y., Mantini, D., Gentili, C., Pan, Z., \& Ding, J. (2010). Selective aberrant functional connectivity of resting state networks in social anxiety disorder. Neurolmage, 52(4), 1549-1558. http://dx.doi.org/10.1016/j. neuroimage.2010.05.010,

Lin, P., De Pisapia, N., \& Jovicich, J. (2011). Intrinsic resting state functional connectivity of default mode network predicts attention task performance. ISMRM, mai, 19.

Liu, Z., Zhang, Y., Bai, L., Yan, H., Dai, R., Zhong, C., \& Wang, H. (2012). Investigation of the effective connectivity of resting state networks in Alzheimer's disease: A functional MRI study combining independent components analysis and multivariate granger causality analysis. NMR in Biomedicine, 25(12), 1311-1320. http://dx.doi.org/10.1002/nbm.2803.

Louapre, C., Perlbarg, V., García-Lorenzo, D., Urbanski, M., Benali, H., Assouad, R., ... Stankoff, B. (2014). Brain networks disconnection in early multiple sclerosis cognitive deficits: An anatomofunctional study. Human Brain Mapping, 35(9), 4706-4717. http://dx.doi.org/10.1002/hbm.22505.

Marcotte, K., Perlbarg, V., Marrelec, G., Benali, H., \& Ansaldo, A. I. (2013). Defaultmode network functional connectivity in aphasia: Therapy-induced neuroplasticity. Brain and Language, 124(1), 45-55. http://dx.doi.org/10.1016/j. bandl.2012.11.004. 
Marrelec, G., Bellec, P., Krainik, A., Duffau, H., Pélégrini-Issac, M., Lehéricy, S., ... Doyon, J. (2008). Regions, systems, and the brain: Hierarchical measures of functional integration in fMRI. Medical Image Analysis, 12(4), 484-496. http://dx. doi.org/10.1016/j.media.2008.02.002.

Marrelec, G., Krainik, A., Duffau, H., Pélégrini-Issac, M., Lehéricy, S., Doyon, J., \& Benali, H. (2006). Partial correlation for functional brain interactivity investigation in functional MRI. NeuroImage, 32(1), 228-237. http://dx.doi.org/ 10.1016/j.neuroimage.2005.12.057.

Marsolais, Y., Perlbarg, V., Benali, H., \& Joanette, Y. (2014). Age-related changes in functional network connectivity associated with high levels of verbal fluency performance. Cortex, 58(septembre), 123-138. http://dx.doi.org/10.1016/ j.cortex.2014.05.007.

McKhann, G., Drachman, D., Folstein, M., Katzman, R., Price, D., \& Stadlan, E. M. (1984). Clinical diagnosis of Alzheimer's disease: Report of the NINCDS-ADRDA work group under the auspices of Department of Health and Human Services Task Force on Alzheimer's Disease. Neurology, 34(7), 939-944.

Menon, V., \& Uddin, L. Q. (2010). Saliency, switching, attention and control: A network model of insula function. Brain Structure $\mathcal{E}$ Function, 214(5-6), 655-667. http://dx.doi.org/10.1007/s00429-010-0262-0.

Miller, E. K., \& Cohen, J. D. (2001). An integrative theory of prefrontal cortex function. Annual Review of Neuroscience, 24, 167-202. http://dx.doi.org/10.1146/ annurev.neuro.24.1.167.

Minoshima, S., Giordani, B., Berent, S., Frey, K. A., Foster, N. L., \& Kuhl, D. E. (1997). Metabolic reduction in the posterior cingulate cortex in very early Alzheimer's disease. Annals of Neurology, 42(1), 85-94. http://dx.doi.org/10.1002/ ana.410420114.

Onoda, K., Ishihara, M., \& Yamaguchi, S. (2012). Decreased functional connectivity by aging is associated with cognitive decline. Journal of Cognitive Neuroscience, 24(11), 2186-2198. http://dx.doi.org/10.1162/jocn_a_00269.

Orliac, F., Naveau, M., Joliot, M., Delcroix, N., Razafimandimby, A., Brazo, P., ... Delamillieure, P. (2013). Links among resting-state default-mode network, salience network, and symptomatology in schizophrenia. Schizophrenia Research, 148(1-3), 74-80. http://dx.doi.org/10.1016/j.schres.2013.05.007.

Palaniyappan, L., \& Liddle, P. F. (2012). Does the salience network play a cardinal role in psychosis? An emerging hypothesis of insular dysfunction. Journal of Psychiatry \& Neuroscience: JPN, 37(1), 17-27. http://dx.doi.org/10.1503/ jpn.100176.

Park, D. C., \& Reuter-Lorenz, P. (2009). The adaptive brain: Aging and neurocognitive scaffolding. Annual Review of Psychology, 60, 173-196. http://dx.doi.org/ 10.1146/annurev.psych.59.103006.093656.

Perlbarg, V., Bellec, P., Anton, J., Pélégrini-Issac, M., Doyon, J., \& Benali, H. (2007). CORSICA: correction of structured noise in fMRI by automatic identification of ICA components. Magnetic Resonance Imaging, 25(1), 35-46. http://dx.doi.org/ 10.1016/j.mri.2006.09.042.

Perlbarg, G., \& Marrelec, V. (2009). NetBrainWork: A toolbox for studying functional interactions in large-scale brain networks in fMRI. Neuroimage, 47. http://dx.doi. org/10.1016/S1053-8119(09)70568-3.

Perlbarg, V., Marrelec, G., Doyon, J., Pelegrini-Issac, M., Lehericy, S., \& Benali, H. (2008). NEDICA: Detection of group functional networks in FMRI using spatial independent component analysis. In Fifth IEEE international symposium on biomedical imaging: From nano to macro, 2008. ISBI 2008 (pp. 1247-1250). http:// dx.doi.org/10.1109/ISBI.2008.4541229.

Pochon, J. B., Levy, R., Fossati, P., Lehericy, S., Poline, J. B., Pillon, B., ... Dubois, B. (2002). The neural system that bridges reward and cognition in humans: An fMRI study. Proceedings of the National Academy of Sciences, 99(8), 5669-5674. http://dx.doi.org/10.1073/pnas.082111099.

Raichle, M. E., MacLeod, A. M., Snyder, A. Z., Powers, W. J., Gusnard, D. A., \& Shulman, G. L. (2001). A default mode of brain function. Proceedings of the National Academy of Sciences, 98(2), 676-682. http://dx.doi.org/10.1073/pnas.98.2.676.

Reuter-Lorenz, P. A., \& Cappell, K. A. (2008). Neurocognitive aging and the compensation hypothesis. Current Directions in Psychological Science, 17(3), 177-182. http://dx.doi.org/10.1111/j.1467-8721.2008.00570.x.

Román, G. C., Tatemichi, T. K., Erkinjuntti, T., Cummings, J. L., Masdeu, J. C., Garcia, J. H., ... Hofman, A. (1993). Vascular dementia diagnostic criteria for research studies: Report of the NINDS-AIREN international workshop. Neurology, 43(2), 250-260.

Rombouts, S. A. R. B., Barkhof, F., Goekoop, R., Stam, C. J., \& Scheltens, P. (2005). Altered resting state networks in mild cognitive impairment and mild Alzheimer's disease: An fMRI study. Human Brain Mapping, 26(4), 231-239. http://dx.doi.org/10.1002/hbm.20160.

Rosso, C., Valabregue, R., Attal, Y., Vargas, P., Gaudron, M., Baronnet, F., \& Bertasi, E. (2013). Contribution of corticospinal tract and functional connectivity in hand motor impairment after stroke. PLoS One, 8(9). http://dx.doi.org/10.1371/ journal.pone.0073164.

Rytty, R., Nikkinen, J., Paavola, L., Elseoud, A. A., Moilanen, V., Visuri, A., \& Tervonen, O. (2013). GroupICA dual regression analysis of resting state networks in a behavioral variant of frontotemporal dementia. Frontiers in Human Neuroscience, 7, 461. http://dx.doi.org/10.3389/fnhum.2013.00461.
Sala-Llonch, R., Arenaza-Urquijo, E. M., Valls-Pedret, C., Vidal-Piñeiro, D., Bargalló, N., Junque, C., \& Bartrés-Faz, D. (2012). Dynamic functional reorganizations and relationship with working memory performance in healthy aging. Frontiers in Human Neuroscience, 6, 152. http://dx.doi.org/10.3389/fnhum.2012.00152.

Seeley, W. W., Menon, V., Schatzberg, A. F., Keller, J., Glover, G. H., Kenna, H., .. Greicius, M. D. (2007). Dissociable intrinsic connectivity networks for salience processing and executive control. The Journal of Neuroscience: The Official Journal of the Society for Neuroscience, 27(9), 2349-2356. http://dx.doi.org/10.1523/ JNEUROSCI.5587-06.2007.

Serra, L., Cercignani, M., Petrosini, L., Basile, B., Perri, R., Fadda, L., ... Bozzali, M. (2011). Neuroanatomical correlates of cognitive reserve in Alzheimer disease. Rejuvenation Research, 14(2), 143-151. http://dx.doi.org/10.1089/rej.2010.1103.

Sestieri, C., Corbetta, M., Romani, G. L., \& Shulman, G. L. (2011). Episodic memory retrieval, parietal cortex, and the default mode network: Functional and topographic analyses. The Journal of Neuroscience: The Official Journal of the Society for Neuroscience, 31(12), 4407-4420. http://dx.doi.org/10.1523/ JNEUROSCI.3335-10.2011.

Shulman, G. L., Fiez, J. A., Corbetta, M., Buckner, R. L., Miezin, F. M., Raichle, M. E., \& Petersen, S. E. (1997). Common blood flow changes across visual tasks: II. Decreases in cerebral cortex. Journal of Cognitive Neuroscience, 9(5), 648-663. http://dx.doi.org/10.1162/jocn.1997.9.5.648.

Smith, S. M., Fox, P. T., Miller, K. L., Glahn, D. C., Fox, P. M., Mackay, C. E., \& Filippini, N. (2014). Correspondence of the brain's functional architecture during activation and rest. Consulté le juillet, $11<$ http://www.pnas.org>.

Solé-Padullés, C., Bartrés-Faz, D., Junqué, C., Vendrell, P., Rami, L., Clemente, I. C., .. Moliuevo, J. L. (2009). Brain structure and function related to cognitive reserve variables in normal aging, mild cognitive impairment and Alzheimer's disease. Neurobiology of aging, 30(7), 1114-1124. http://dx.doi.org/10.1016/j. neurobiolaging.2007.10.008.

Sorg, C., Riedl, V., Mühlau, M., Calhoun, V. D., Eichele, T., Läer, L., \& Drzezga, A (2007). Selective changes of resting-state networks in individuals at risk for Alzheimer's disease. Proceedings of the National Academy of Sciences of the United States of America, 104(47), 18760-18765. http://dx.doi.org/10.1073/ pnas.0708803104.

Sridharan, D., Levitin, D. J., \& Menon, V. (2008). A critical role for the right frontoinsular cortex in switching between central-executive and default-mode networks. Proceedings of the National Academy of Sciences of the United States of America, 105(34), 12569-12574. http://dx.doi.org/10.1073/pnas.0800005105.

Stern, Y. (2009). Cognitive reserve. Neuropsychologia, 47(10), 2015-2028. http://dx doi.org/10.1016/j.neuropsychologia.2009.03.004.

Taylor, K. S., Seminowicz, D. A., \& Davis, K. D. (2009). Two systems of resting state connectivity between the insula and cingulate cortex. Human Brain Mapping, 30 (9), 2731-2745. http://dx.doi.org/10.1002/hbm.20705.

The 3C Study Group (2003). Vascular factors and risk of dementia: Design of the Three-City Study and baseline characteristics of the study population. Neuroepidemiology, 22(6), 316-325. http://dx.doi.org/10.1159/000072920.

Uddin, L. Q., Clare Kelly, A. M., Biswal, B., Castellanos, F. X., \& Milham, M. P. (2009) Functional connectivity of default mode network components: Correlation, anticorrelation, and causality. Human Brain Mapping, 30(2). http://dx.doi.org/ $10.1002 / \mathrm{hbm} .20531$.

Uddin, L. Q., \& Menon, V. (2010). Introduction to special topic - Resting-state brain activity: Implications for systems neuroscience. Frontiers in Systems Neuroscience, 4(août). http://dx.doi.org/10.3389/fnsys.2010.00037.

Wang, L., Zang, Y., He, Y., Liang, M., Zhang, X., Tian, L., ... Li, K. (2006). Changes in hippocampal connectivity in the early stages of Alzheimer's disease: Evidence from resting state fMRI. NeuroImage, 31(2), 496-504. http://dx.doi.org/10.1016/ j.neuroimage.2005.12.033.

Weissman-Fogel, I., Moayedi, M., Taylor, K. S., Pope, G., \& Davis, K. D. (2010) Cognitive and default-mode resting state networks: Do male and female brains "Rest" differently? Human Brain Mapping, 31(11), 1713-1726. http://dx.doi.org/ $10.1002 / \mathrm{hbm} .20968$.

Wu, X., Li, R., Fleisher, A. S., Reiman, E. M., Chen, K., \& Yao, L. (2011). Altered default mode network connectivity in Alzheimer's disease - A resting functional MRI and Bayesian network study. Human Brain Mapping, 32(11), 1868-1881. http:// dx.doi.org/10.1002/hbm.21153.

Xue, T., Yuan, K., Zhao, L., Yu, D., Zhao, L., Dong, T., ... Tian, J. (2012). Intrinsic brain network abnormalities in migraines without aura revealed in resting-state fMRI. PLoS One, 7(12), e52927. http://dx.doi.org/10.1371/journal.pone.0052927.

Zarahn, E., Rakitin, B. C., Abela, D., Flynn, J., \& Stern, Y. (2006). Distinct spatial patterns of brain activity associated with memory storage and search. Neurolmage, $\quad 33(2), \quad$ 794-804. http://dx.doi.org/10.1016/j. neuroimage.2006.07.020.

Zarahn, E., Rakitin, B., Abela, D., Flynn, J., \& Stern, Y. (2007). Age-related changes in brain activation during a delayed item recognition task. Neurobiology of Aging, 28(5), 784-798. http://dx.doi.org/10.1016/j.neurobiolaging.2006.03.002. 